\section{A young woman concerned about mercury}

\author{
Stefanos N. Kales MD MPH, Aaron M.S. Thompson MD MPH
}

A healthy 30-year-old woman is planning to conceive. She seeks advice on having her dental amalgam fillings removed because of concerns about mercury toxicity. She also asks to be tested for mercury.

\section{What questions should be asked to assess the patient's exposure to mercury?}

The patient should be asked about potential sources of elemental, inorganic and organic mercury (Appendix 1, available at www.cmaj.ca/lookup/ suppl/doi:10.1503/cmaj.150669/-/DC1). ${ }^{1}$ A dietary history documenting the types and amount of fish consumed (especially large predatory fish, such as tuna, swordfish and shark) will provide information on potential exposure to organic mercury (methylmercury). Dental amalgam releases small amounts of elemental mercury vapour. Therefore, the physician should inquire about the number and integrity of the patient's fillings, her chewing habits and bruxism. In the occupational history, the physician should inquire about working with or around processes involving mercury. ${ }^{1}$ Inadvertent inhalation of mercury vapour from broken instrumentation or fluorescent light bulbs is another potential, albeit infrequent, source of exposure to elemental mercury. ${ }^{1}$ Patients may also come into contact with inorganic mercury salts through topical antiseptics on disrupted skin or other tissues.

Although not a clinically relevant source of mercury, patients may have concerns about the vaccine preservative thimerosal, which is partly metabolized to ethylmercury. Ethylmercury is less neurotoxic than methylmercury and is more rapidly excreted. ${ }^{2}$ Thimerosal is not used in pediatric vaccines in Canada other than those for influenza; similarly, it is generally not used in adult vaccines, with only a few exceptions, such as some hepatitis B preparations. A case-control study indicated that levels of mercury in infants who received routine immunization with thimerosalcontaining vaccines did not exceed guidelines for methylmercury. ${ }^{3}$ Moreover, prenatal and early-life exposure to ethylmercury from thimerosalcontaining vaccines does not increase the risk of autism, according to the results of case-control and retrospective cohort studies. ${ }^{4,5}$

\section{What should be included in the history} and physical examination for this patient? Symptom history and physical examination generally do not contribute to a clinical assessment of mercury because levels are almost always well below toxicity thresholds. In rare instances of high intake of large predatory fish, the focus of the clinical evaluation is the central nervous system. Signs and symptoms documented in historical poisoning outbreaks include perioral paresthesia, dysarthria, visual field defects and ataxia. ${ }^{1}$ In cases of occupational or inadvertent inhalation of mercury vapour, the clinical assessment should focus on the central nervous system (tremor, ataxia, emotional instability), the peripheral nervous system (distal sensory loss) and the renal system. ${ }^{1}$

\section{Should mercury testing be ordered for this patient?}

Testing is generally not indicated but may be considered in cases of high consumption of large predatory fish or exposure to mercury vapour (inadvertent or occupational) (Box 1). ${ }^{6}$ If such testing is clinically indicated, it is prudent to order measurement of both blood and urine mercury levels. Blood mercury primarily reflects methylmercury (from consumption of fish), whereas urine mercury corrected for creatinine concentration primarily reflects exposure to elemental and inorganic mercury. ${ }^{7}$ Unconventional testing methods (e.g., commercial hair analysis, urine mercury challenge or "provoked" testing using a chelator) should be avoided. ${ }^{8}$

Before ordering a mercury test, the physician should explain to the patient that laboratory reference ranges are population averages and do not reflect toxicity thresholds. Blood mercury levels are usually less than $25 \mathrm{nmol} / \mathrm{L}(5 \mu \mathrm{g} / \mathrm{L})$ among those who eat little fish, whereas levels up to $100 \mathrm{nmol} / \mathrm{L}$ $(20 \mu \mathrm{g} / \mathrm{L})$ may be seen in people who eat fish four to seven times a week. Urine mercury levels are also generally below $25 \mathrm{nmol} / \mathrm{L}(5 \mu \mathrm{g} / \mathrm{L}) .{ }^{9}$ In con-
Competing interests: None declared.

This article has been peer reviewed.

The clinical scenario is fictional.

Correspondence to: Stefanos Kales, skales@hsph.harvard.edu

CMAJ 2016. DOI:10.1503 /cmaj.150669 


\section{Box 1: Choosing Wisely Canada recommendation on mercury testing ${ }^{6}$}

Don't order blood mercury testing unless dietary history suggests risk, the patient is pregnant or planning to become pregnant, and/or the patient is occupationally exposed to organomercury compounds.

- For adults, Health Canada's guidance value for total blood mercury concentrations is $40 \mathrm{nmol} / \mathrm{L}(8 \mu \mathrm{g} / \mathrm{L})$ for women of child-bearing age and $100 \mathrm{nmol} / \mathrm{L}(20 \mu \mathrm{g} / \mathrm{L})$ for women $\geq 50$ years and men $>18$ years.

- Although clinically significant exposures may still occur in Canada, less than $1 \%$ of Canadian adults have total blood mercury concentrations above Health Canada's guidance value. As such, the large majority of individuals who present with concerns about metal toxicity do not actually have toxicity, and testing results in false positives (values above the reference range but not in the range of toxicity).

- Occupationally exposed workers and women of child-bearing age are susceptible subgroups; therefore, testing in these populations is warranted in cases where a careful occupational and/or environmental history suggests significant exposure.

- In the absence of clinical presentation and history indicating a risk of toxicity, testing should be avoided because it may lead to misinterpretation and unnecessary concern or interventions (dietary restriction, chelation) that may cause harm. fillings and was given information from the Canadian Dental Association (https://www.cda-adc. ca/_files/position_statements/amalgam.pdf). The patient reported eating two to three fish meals per week and was reassured that, on the basis of her exposure history, mercury testing was not indicated. She was counselled to continue to include fish in her diet and was given information on relative amounts of methylmercury in different fish species, along with Health Canada's advice on fish consumption (www.hc-sc.gc.ca/fn-an/securit/chem -chim/environ/mercur/cons-adv-etud-eng.php).

\section{References}

1. Clarkson TW, Magos L, Myers GJ. The toxicology of mercury - current exposures and clinical manifestations. $N$ Engl $\mathrm{J}$ Med 2003;349:1731-7.

2. Magos L. Review on the toxicity of ethyl mercury including its presence as a preservative in biological and pharmaceutical preparations. J Appl Toxicol 2001;21:1-5.

3. Pichichero ME, Cernichiari E, Lopreiato J, et al. Mercury concentrations and metabolism in infants receiving vaccines containing thiomersal: a descriptive study. Lancet 2002;360:1737-41.

4. Price CS, Thompson WW, Goodson B, et al. Prenatal and infant exposure to thimerosal from vaccines and immunoglobulins and risk of autism. Pediatrics 2010;126:656-64.

5. Andrews N. Thimerosal exposure in infants and developmental disorders: a retrospective cohort study in the United Kingdom does not support a causal association. Pediatrics 2004;114:584-91.

6. Occupational Medicine Specialists of Canada. Occupational medicine: five things physicians and patients should question. Choosing Wisely Canada; 2014. Available: www.choosingwisely canada.org/recommendations/occupational-medicine-specialists -of-canada-2/ (accessed 2015 Nov. 3).

7. Kales SN, Goldman RH. Mercury exposure: current concepts, controversies, and a clinic's experience. J Occup Environ Med 2002; 44:143-54

8. Felton DJ, Kales SN, Goldman RH. An update and review of unconventional metals testing and treatment. Toxics 2014;2:403-16.

9. Legrand M, Feeley M, Tikhonov C, et al. Methylmercury blood guidance values for Canada. Can J Public Health 2010;101:28-31.

10. Apostoli P, Cortesi I, Mangili A, et al. Assessment of reference values for mercury in urine: the results of an Italian polycentric study. Sci Total Environ 2002;289:13-24.

11. Lauterbach M, Martins IP, Castro-Caldas A, et al. Neurological outcomes in children with and without amalgam-related mercury exposure: seven years of longitudinal observations in a randomized trial. J Am Dent Assoc 2008;139:138-45.

12. Mahaffey KR, Sunderland EM, Chan HM, et al. Balancing the benefits of n-3 polyunsaturated fatty acids and the risks of methylmercury exposure from fish consumption. Nutr Rev 2011; 69:493-508.

Affiliations: Environmental and Occupational Medicine and Epidemiology (Kales), Harvard T.H. Chan School of Public Health, Harvard University, Boston, Mass.; The Cambridge Health Alliance (Kales), Harvard Medical School, Cambridge, Mass.; Faculty of Medicine (Thompson) and Dalla Lana School of Public Health (Thompson), University of Toronto, Toronto, Ont.; Department of Occupational and Environmental Health (Thompson), St. Michael's Hospital, Toronto, Ont.

Contributors: Both of the authors contributed substantially to the conception and design of the manuscript, drafted the article and revised it critically for important intellectual content, gave final approval of the version to be published and agreed to act as guarantors of the work.

CMAJ is collaborating with Choosing Wisely Canada (www.choosingwiselycanada.org), with support from Health Canada, to publish a series of articles describing how to apply the Choosing Wisely Canada recommendations in clinical practice. 